\title{
Treating coral bleaching as weather: A framework to validate and optimize prediction skill
}

\author{
Thomas M DeCarlo ${ }^{\text {Corresp. 1,2 }}$ \\ 1 Hawaii Pacific University, Honolulu, HI, United States \\ 2 Red Sea Research Center, Division of Biological and Environmental Science and Engineering, King Abdullah University of Science and Technology, \\ Thuwal, Saudi Arabia \\ Corresponding Author: Thomas M DeCarlo \\ Email address: tdecarlo@hpu.edu
}

Few coral reefs remain unscathed by mass bleaching over the past several decades, and much of the coral reef science conducted today relates in some way to the causes, consequences, or recovery pathways of bleaching events. Most studies portray a simple cause and effect relationship between anomalously high summer temperatures and bleaching, which is understandable given that bleaching rarely occurs outside these unusually warm times. However, the statistical skill with which temperature captures bleaching is hampered by many "false alarms", times when temperatures reached nominal bleaching levels, but bleaching did not occur. While these false alarms are often not included in global bleaching assessments, they offer valuable opportunities to improve predictive skill, and therefore understanding, of coral bleaching events. Here, I show how a statistical framework adopted from weather forecasting can optimize bleaching predictions and validate which environmental factors play a role in bleaching susceptibility. Removing the $1^{\circ} \mathrm{C}$ above the maximum monthly mean cutoff in the typical degree heating weeks (DHW) definition, adjusting the DHW window from 12 to 9 weeks, using regional-specific DHW thresholds, and including an El Niño threshold already improves the model skill by $45 \%$. Most importantly, this framework enables hypothesis testing of other factors or metrics that may improve our ability to forecast coral bleaching events. 
1 Treating coral bleaching as weather: a framework to validate and optimize prediction skill

2

3 Thomas M. DeCarlo ${ }^{1,2 *}$

$4 \quad{ }^{1}$ Hawaii Pacific University, Honolulu, HI

$5{ }^{2}$ Red Sea Research Center, Division of Biological and Environmental Science and Engineering,

6 King Abdullah University of Science and Technology (KAUST), Thuwal, Saudi Arabia

7

8 *tdecarlo@hpu.edu

9 


\section{Abstract}

Few coral reefs remain unscathed by mass bleaching over the past several decades, and

12 much of the coral reef science conducted today relates in some way to the causes, consequences,

13 or recovery pathways of bleaching events. Most studies portray a simple cause and effect

14 relationship between anomalously high summer temperatures and bleaching, which is

15 understandable given that bleaching rarely occurs outside these unusually warm times. However,

16 the statistical skill with which temperature captures bleaching is hampered by many "false

17 alarms", times when temperatures reached nominal bleaching levels, but bleaching did not occur.

18 While these false alarms are often not included in global bleaching assessments, they offer

19 valuable opportunities to improve predictive skill, and therefore understanding, of coral

20 bleaching events. Here, I show how a statistical framework adopted from weather forecasting

21 can optimize bleaching predictions and validate which environmental factors play a role in

22 bleaching susceptibility. Removing the $1^{\circ} \mathrm{C}$ above the maximum monthly mean cutoff in the

23 typical degree heating weeks (DHW) definition, adjusting the DHW window from 12 to 9 weeks,

24 using regional-specific DHW thresholds, and including an El Niño threshold already improves

25 the model skill by $45 \%$. Most importantly, this framework enables hypothesis testing of other

26 factors or metrics that may improve our ability to forecast coral bleaching events. 


\section{Introduction}

29

30

31

32

33

34

Coral bleaching, the loss of the symbiotic zooxanthellae algae that live within coral tissues, is recognized as one of the primary threats facing reef-building corals today. Although bleaching is occasionally observed in isolated or scattered coral colonies, "mass bleaching events" occur when multiple species across entire reefs bleach at once. The link between mass coral bleaching and unusually warm water temperature was established in the wake of the widespread 1982-83 El Niño, which caused severe bleaching across the Pacific Ocean (Glynn, 1983, 1993; Coffroth, Lasker \& Oliver, 1990). Since then, bleaching events have become more frequent (Hughes et al., 2018), and have continued to coincide with anomalously high

temperatures (e.g., Bruno et al. 2001; DeCarlo et al. 2017; Donner et al. 2017; Hughes et al. 2017; Barkley et al. 2018; Sully et al. 2019). Yet, some high-temperature events have not caused bleaching (Thompson \& van Woesik, 2009; Pratchett et al., 2013; Gintert et al., 2018; DeCarlo \& Harrison, 2019). The absence of bleaching is often not included in large-scale analyses of coral bleaching (but see e.g., Sully et al. 2019), which precludes a statistical validation of the skill of temperature in predicting bleaching events. Rather, our ability to predict bleaching, and to understand the causes of these events, depends on correctly capturing both the presence and absence of bleaching.

One way to critically assess our understanding of the causes of coral bleaching is to view these events within a weather-forecasting framework (van Hooidonk \& Huber, 2009).

7 Meteorologists have a strong understanding of the factors that cause precipitation, and they are able to predict when and where there will be rain or snow based on wind, temperature, and pressure patterns. Intuitively, we want to know both when rain will fall, and when it will not. Forecasting rain when it is actually sunny is deemed just as bad as forecasting clear skies when it 
51 actually rains. We should view coral bleaching in the same way. Fortunately, the statistical tools

52 to do so are already in place because weather forecasters have been validating and optimizing

53 their predictions for decades. Here, I apply weather forecasting statistics to a global coral

54 bleaching database to (1) evaluate the skill of bleaching predictions, and (2) explore various

55 approaches to improve prediction skill. Additionally, since the choice of sea surface temperature

56 (SST) product affects bleaching predictions (DeCarlo \& Harrison, 2019), as a first step I evaluate

57 the agreement between various SST products in terms of representing global mean anomalies.

59 Methods

60 To assess the agreement between the various SST products that could be used here to

61 predict coral bleaching, I calculated global-mean annual SST anomalies using six datasets:

62 Coral Reef Watch's CoralTemp (CRW) (Liu et al., 2014), Optimum Interpolation SST (OI-

63 SSTv2) (Reynolds et al., 2007; Banzon et al., 2016), the Canadian Meteorological Center (CMC)

64 (2012), the Extended Reconstructed SST version 5 (ERSSTv5) (Huang et al., 2017), the Met

65 Office Hadley Centre SST version 4 (HadSST4) (Kennedy et al., 2019), and the Japan

66 Meteorological Agency (JMA) Centennial In Situ Observation-Based Estimates of SST

67 (COBE2) (Hirahara, Ishii \& Fukuda, 2014). Comparing global-mean annual SST anomalies is a

68 coarse evaluation since it does not account for potentially important differences on relatively

69 small spatial and temporal scales. Nevertheless, this type of analysis is common for evaluations

70 of SST products (Huang et al., 2018), and it can identify the broad-scale differences among

71 products. I performed a principal component analysis (PCA) to evaluate how SST products

72 cluster together. Additionally, I calculated pair-wise annual differences between the products to

73 identify any consistent discrepancies between products. 
The key to applying weather forecasting statistics to coral bleaching is a database

75

76

77

78

79

80

81

82

83

84

85

86

87

88

89

complete with both presence and absence of bleaching, which only recently became available

(Hughes et al., 2018). Other databases, such as the bleaching reports in ReefBase, are unsuitable

because they are dominated by reports of bleaching and include relatively few observations of

the absence of bleaching (e.g., see Logan et al., 2012). The complete database of Hughes et al. (2018), however, enables the application of binary (presence/absence) event detection metrics that are commonly used to evaluate weather forecasts. In addition to bleaching absences, this database includes "moderate" (1-30\% bleaching) and "severe" (greater than 30\% bleaching) events, but for most analyses here the moderate and severe events are combined to reduce the data to bleaching presence/absence (but see exception below when only severe events are considered). All of the binary metrics are based on a simple contingency table of predictions versus observations (Table 1). No single metric can capture all the information in the dataset, and thus a variety of metrics are used to evaluate predictive skill (Table 2). Together, these metrics can be used to validate whether a predictor performs better than random chance, and to optimize the threshold of a continuous predictor used to forecast events. Metrics focused on one aspect of the prediction skill (Accuracy, Probability of Detection, Bias, Probability of False Detection, and False Alarm Ratio) generally change monotonically with the DHW threshold. Thus, while these metrics hold key information, they do not clearly provide an optimal threshold. Conversely, the Equitable Threat Score (ETS) accounts for multiple aspects of the forecast, rewarding correct predictions and penalizing incorrect ones (Hamill, 1999). ETS is the most commonly used threshold optimizer in weather forecasts (ECMWF, 2018), and it is adopted here as a guide for coral bleaching predictions. It is worth noting that ETS and the related Pierce's Skill Score have previously been applied to evaluate coral bleaching (van Hooidonk \& Huber, 2009; Mollica et 
97 al., 2019), but not yet on a dataset like Hughes et al. (2018) that is complete with both presence

98

99

100

101

102

103

104

105

106

107

108

109

110

111

112

113

114

115

116

117

118

119

and absence. Additionally, there are other skill scores in use (Table 2), which are insightful under

some circumstances, but are generally considered less robust and are used less frequently by weather forecasters.

The SST product OI-SSTv2 was identified as the most appropriate for this analysis due to its relatively high resolution ( $\sim 25-\mathrm{km}$ and daily), temporal coverage from 1982 to present, and agreement with most other SST datasets (see Results and Discussion). Further supporting the use of OI-SSTv2 here is that it is designed to minimize temporal bias by using a single type of sensor, the advanced very high resolution radiometer (AVHRR) (Banzon et al., 2016). Indeed, in a comparison of satellite SST to in situ reef-water temperature measured by loggers on the Great Barrier Reef, OI-SSTv2 was more consistent over time than other SST products, especially in terms of representing the highest summer temperatures (DeCarlo \& Harrison, 2019).

Here, I used OI-SSTv2 as a predictor of coral bleaching events at 100 globally-distributed reef sites between 1982 and 2016 (using the database of Hughes et al., 2018). I calculated degree heating weeks (DHW) from OI-SSTv2, defining the climatological maximum monthly mean (MMM) based on 1982-2012. DHW incorporates both the magnitude and duration of SST anomalies above the MMM, and is commonly used as a predictor of coral bleaching (Liu, Strong \& Skirving, 2003; Liu et al., 2006; Hughes et al., 2017). Since many of the reef areas in the database are larger than $25 \mathrm{~km}$, I used the maximum annual DHW among the grid-box closest to the database coordinates and its neighbors. The database as published in Hughes et al. (2018) required fixing coordinates for 13 out of 100 sites (Supplement Table S1). Additionally, bleaching in the central and northern Great Barrier Reef was incorrectly labeled in the original database as moderate in 1983, when the literature on this event indicates that it was instead a 
120 severe event in 1982 (Fisk \& Done, 1985; Harriott, 1985; Oliver, 1985). Likewise, 1987

121 bleaching in the Galápagos Islands was reported as severe, but the literature clearly shows that

122 this was a moderate event (Podestá \& Glynn, 1997; Glynn et al., 2001, 2017). Finally, no

123 bleaching occurred in the Al Lith region of the Red Sea during 2010 (event removed because no

124 literature supports this event). The adjustments I made to the bleaching histories from the

125 database as published in Hughes et al. (2018) improved the statistical skill, albeit only slightly

126 since my changes affected relatively few entries in the database (Supplement Tables S2-3). Even

127 though the database was presented as being temporally complete (i.e., the authors implied that

128 the full history of bleaching during 1980-2016 was known at each of the 100 sites), it is possible

129 that other inaccuracies exist in the database, including either mislabeling as noted above or

130 bleaching events that went unnoticed. Nevertheless, except for the noted corrections, I took the

131 database at face value since no alternative global databases are suitable for this study.

132 Additionally, I explored whether patterns in the database are indicative of unnoticed bleaching

133 events in the early part of the database by evaluating whether (1) false alarms decrease and (2)

134 ETS increases over time.

135 The common definition of DHW includes a $1{ }^{\circ} \mathrm{C}$ above the MMM cutoff for

136 accumulating heat stress, and DHW are calculated over the preceding 12 weeks. In initial

137 analyses, I tested whether removing the $1{ }^{\circ} \mathrm{C}$ cutoff (i.e., DHW begin accumulating as soon as

138 SST exceeds the MMM), and using time windows shorter than 12 weeks, improved the results. I

139 also varied the DHW threshold used to predict bleaching between 1 and $15^{\circ} \mathrm{C}$-weeks to find the

140 optimal value. In subsequent analyses, I evaluated whether prediction skill increased when using

141 regional-specific DHW thresholds, and including an additional El Niño threshold (based on the

142 Niño3.4 SST anomaly definition of El Niño). Additionally, I evaluated if maximum Hotspots 
143 (SST anomalies above the MMM) or the Marine Heatwave index (Hobday et al., 2018)

144 performed better than DHW since some analyses of coral bleaching events have found these

145 shorter-term metrics to be most effective (Berkelmans et al., 2004; Genevier et al., 2019).

146 Finally, I tested whether there is evidence for an increase in the bleaching threshold over time.

147

148 Results and Discussion

149 Choice of SST product

150 A variety of SST products are available that include a range of spatial resolution $(\sim 5 \mathrm{~km}$

151 to over $200 \mathrm{~km}$ ), temporal resolution (daily to monthly), temporal coverage (several decades to

152 beyond a century), and methods for bias correction. These products can broadly be classified into

153 two groups: coarse-resolution centennial-scale datasets that rely heavily on in situ observations

154 (but may include satellite data), and higher resolution datasets beginning in the 1980s that are

155 based on satellite observations (but may use in situ data for bias corrections). Satellite-based

156 products are most commonly used for coral bleaching studies due to their higher resolution (e.g.,

157 Liu et al., 2014), but it is crucial to recognize that important differences exist between these

158 products (e.g., DeCarlo \& Harrison, 2019), likely resulting from the use of different satellite data

159 and the techniques used for bias correction. Thus, the choice of satellite-based SST product can

160 lead to different conclusions in analyses of the drivers of coral bleaching events (DeCarlo \&

161 Harrison, 2019).

162 My analysis of global-mean annual SST anomalies indicates that Coral Reef Watch is a

163 clear outlier from the five other products (Fig. 1). This is evident in both the PCA (Fig. 1C) and

164 pairwise comparisons among products (Fig 1D-H; see also Supplemental Fig. S1). Since the five

165 other products cluster relatively close together (Fig. 1C), even though they are based on partially 
166 different source data and different methods, it would be difficult to conclude that the relatively

167 large disparity in Coral Reef Watch represents a more accurate version of SST. Pair-wise

168 comparisons between Coral Reef Watch and the other products show a temporal pattern in which

169 Coral Reef Watch underestimates SST from the mid-1990s to the early 2000s, a pattern that is

170 also represented by the $2^{\text {nd }}$ principal component (Fig. 1D-H). A similar temporal change in bias

171 between Coral Reef Watch and in situ loggers was also found on the Great Barrier Reef, in

172 which Coral Reef Watch underestimated reef-water temperatures during 1998, 2002, and 2004

173 (DeCarlo \& Harrison, 2019). Additionally, the root-mean-square error (RMSE) between Coral

174 Reef Watch and other SST products is $0.04-0.07^{\circ} \mathrm{C}$, whereas all other pair-wise combinations

175 have RMSE $\leq 0.04{ }^{\circ} \mathrm{C}$ (Supplemental Fig. S1). While these differences may seem small, they are

176 sufficient to substantially change DHW, and more detailed analyses on the Great Barrier Reef

177 showed that the differences are exacerbated in the summer months (DeCarlo \& Harrison, 2019).

178 Thus, even though Coral Reef Watch performs well during the past decade (DeCarlo et al., 2019;

179 DeCarlo \& Harrison, 2019; Claar, Cobb \& Baum, 2019), I conclude that it has inaccuracies in

180 earlier times that render it inappropriate for multi-decadal analyses of past coral bleaching

181 events. Since the other products are limited by either coarse spatial and temporal resolution

182 (ERSSTv5, HadSST4, COBE2) or temporal coverage (CMC, which only begins in 1992), this

183 leaves OI-SSTv2 as the most suitable SST product to analyze past coral bleaching events

184 globally since 1982.

185

186 The skill of predicting coral bleaching and how to improve it

187 The numbers of hits, misses, false alarms, and correct negatives vary systematically with

188 the DHW threshold. As this threshold is raised, the numbers of hits decrease, misses increase, 
189 false alarms decrease, and correct negatives increase (Fig. 2). This reveals that there are tradeoffs

190 involved in setting the DHW threshold, and these need to be evaluated carefully. For instance,

191 using a low DHW threshold of $2{ }^{\circ} \mathrm{C}$-weeks maximizes the number of hits and minimizes the

192 number of misses, both of which are beneficial features of a forecast. However, such a low DHW

193 threshold produces a large number of false alarms, typically more than half of reef sites each

194 year. These tradeoffs can be quantified in various ways by inspecting how the binary metrics

195 (Table 2) change with the DHW threshold (Figs. 3-4). In particular, the Equitable Threat Score

196 (ETS) provides an objective way to define the optimal DHW, which in this case was $6.3^{\circ} \mathrm{C}$ -

197 weeks (when using DHW defined over a 12-week window).

198

Initial analyses were conducted to determine the best way to define heat stress (Fig. 3 and

199 Table 3). Removing the $1{ }^{\circ} \mathrm{C}$ cutoff for accumulating heat stress, and setting the DHW time

200 window to 9 weeks, both improved prediction skill (higher maximum ETS; Fig 3B). Thus, all

201 further analyses were conducted with DHWs accumulating anytime SST exceeded the MMM

202 over the preceding 9 weeks. With this definition, the optimal DHW for predicting bleaching

203 events was $5.4^{\circ} \mathrm{C}$-weeks. Using either maximum annual Hotspot or MHW decreased prediction

204 skill (Fig. 3B), likely because both metrics represent only magnitude (not duration) of heat stress,

205 and because MHW is not restricted to summer months (i.e., a winter heatwave is unlikely to

206 cause bleaching). Since restricting MHW to summer months would make it effectively the same

207 as Hotspots, and incorporating heatwave duration would make it similar to DHW, there is little

208 utility in the MHW index for coral bleaching. Prediction skill was higher for only severe, rather

209 than all, bleaching events, and the optimal DHW threshold (the DHW at which ETS is

210 maximized) was higher for severe events. These results are consistent with severe bleaching 
211 being a result of more intense heat stress, which makes these events easier to separate from non212 bleaching events.

213 The ETS varies among regions, with the Indian Ocean and Middle East performing the 214 best, and the Western Atlantic performing the worst (Fig. 4). Evaluations of weather forecasts 215 often consider ETS alongside Bias because ETS tends to reward hits most favorably, and as a 216 result ETS sometimes suggests a threshold with a large positive Bias (i.e., more events are 217 forecast than actually occur). At the optimal DHW threshold, the Bias is relatively close to 1 218 (0.96) for the Indian Ocean and Middle East, whereas the Bias reaches 1.69 for the Pacific.

219 When all regions are considered together, the ETS is 0.169 and the Bias is 1.27. Using a 220 regional-specific DHW threshold improves the global ETS to 0.2035 (Table 3). As context for 221 these ETS values, weather forecasts predicting rain the following day in the United States and 222 Europe have an ETS of around 0.4, and rain predictions made a week in advance have an ETS of 2230.15 (ECMWF, 2018). It is important to note that the relatively low ETS of bleaching predictions 224 could reflect a variety of errors. In addition to imperfections in DHW as a predictor, potential 225 errors include inaccuracies in the bleaching database (e.g., unreported bleaching events), or 226 disparities in spatial scales between bleaching and satellite-based SST (i.e., localized warming in 227 reef micro-climates may not be detected in 25-km grid-boxes). Although the potential for 228 bleaching under localized warming is difficult to test retrospectively, if there were more 229 unreported bleaching events earlier in the database, more false alarms would be expected further 230 back in time. However, there are fewer false alarms during 1982-1999 than 2000-2016 (Fig. 2B), 231 even though most reefs were probably monitored less in earlier years. Further, there is no 232 significant trend over time in ETS (Supplement Fig. S2) as might be expected if the accuracy of 
233 the database improved over time. Therefore, while it remains possible that inaccuracies exist in

234 the database, the patterns in model skill over time do not suggest that this is a major issue.

235 One key advantage of the weather forecasting approach is that ETS can be used to

236 objectively test whether other factors modulate the relationship between temperature and

237 bleaching. For example, I tested whether ETS improves with the inclusion of a second predictor:

238 (1) a DHW-threshold trend or (2) El Niño conditions (Fig. 5). A trend in the DHW threshold

239 over time could arise either if corals acclimatize to more frequent heatwaves, or if bleaching

240 events selectively kill the most susceptible species or individuals. For simplicity, I assume any

241 change in the DHW threshold has occurred linearly, although this may be less applicable to

242 changes in heat tolerance following selective mortality events. Previous analyses have concluded

243 that the DHW threshold has increased (Guest et al., 2012; Logan et al., 2014; Hughes et al.,

244 2019; DeCarlo et al., 2019; Sully et al., 2019). However, the ETS-based analysis presented here

245 indicates that including any trend in the DHW threshold does not improve the ETS (the top 2\%

246 of ETS values overlap with zero trend), and therefore the null hypothesis that the DHW threshold

247 has remained constant cannot be rejected. Additionally, El Niño alters the coupled ocean-

248 atmosphere circulation globally, and thus E1 Niño could affect bleaching independently of

249 temperature through a variety of mechanisms linked to, for example, winds or clouds (Smith,

250 2001; DeCarlo et al., 2017; Baird et al., 2017). ETS improves from 0.169 to 0.198 (or to 0.218 if

251 using regional-specific DHW thresholds; Table 3) when including El Niño as an additional

252 threshold, and critically, the highest ETS values are associated with stronger than normal El Niño

253 conditions (Fig. 5). This is clear evidence that El Niño modulates coral bleaching across the

254 tropics through mechanisms beyond just SST because greater skill (higher ETS) is achieved

255 when the El Niño threshold is used in combination with DHW, rather than using DHW alone. 
256 Elucidating these non-temperature mechanisms by which El Niño influences bleaching should

257 therefore represent a high priority for future research.

258

259 Conclusions

260 Temperature extremes are undoubtedly the primary driver of coral bleaching, but they

261 may not be the only factor involved. Light, nutrients, previous stress history, temperature

262 variance, and rate of warming, among other factors, have all been evoked as contributors to

263 bleaching susceptibility (Thompson \& van Woesik, 2009; Skirving et al., 2017; Safaie et al.,

264 2018; DeCarlo \& Harrison, 2019; Lapointe et al., 2019). While satellite-derived SST data are

265 easy to access, relying on temperature alone to predict bleaching events could lead to

266 overconfidence in its role relative to other factors. Indeed, it may seem surprising that we should

267 put only as much confidence in our ability to reconstruct bleaching events from temperature as

268 we put in rain forecast for next week. The reliability of weather forecasts has improved

269 dramatically over time as a result of continuous evaluation and optimization of the predictor

270 variables. Surely, our ability to predict - and therefore to understand - coral bleaching events can

271 also improve, if critically evaluated within the statistical framework provided by weather

272 forecasting. Removing the $1{ }^{\circ} \mathrm{C}$ above the MMM cutoff in the DHW definition, adjusting the

273 DHW window from 12 to 9 weeks, using regional-specific DHW thresholds, and including an El

274 Niño threshold already improves ETS by $45 \%$. My analysis of various predictors is not

275 exhaustive as other heat stress metrics are possible, such as including temperature variance or the

276 beneficial effects of cooling respites during heat stress (e.g., Logan et al. 2012, 2014; Ainsworth

277 et al. 2016; Safaie et al. 2018; McClanahan et al. 2019). Rather, the analyses presented here are a

278 demonstration of how ETS can be used to test hypotheses regarding which aspect(s) of 
279 temperature and/or other factors are most strongly correlated to bleaching events. Setting our 280 sights on achieving even greater skill will be essential for informing management decisions 281 based on coral sensitivity to heat stress (e.g., Beyer et al. 2018; Darling et al. 2019).

282

283

284

285

286

287

288

289

290

291

292

293

294

295

296

297

298

299

300

301

\section{Data accessibility:}

Raw data and code are available at: https://codeocean.com/capsule/2363485

\section{References:}

Ainsworth TD, Heron SF, Ortiz JC, Mumby PJ, Grech A, Ogawa D, Eakin CM, Leggat W. 2016. Climate change disables coral bleaching protection on the Great Barrier Reef. Science 352:338-342. DOI: 10.1126/science.aac7125.

Baird AH, Keith SA, Woolsey E, Yoshida R, Naruse T. 2017. Rapid coral mortality following doldrums-like conditions on Iriomote, Japan. F1000Research 6:1728. DOI: 10.12688/f1000research.12660.1.

Banzon V, Smith TM, Chin TM, Liu C, Hankins W. 2016. A long-term record of blended satellite and in situ sea-surface temperature for climate monitoring, modeling and environmental studies. Earth System Science Data 8:165-176. DOI: 10.5194/essd-8-1652016.

Barkley H, Cohen A, Mollica N, Brainard R, Rivera H, DeCarlo T, Lohmann G, Drenkard E, Alpert A, Young C, Vargas-Angel B, Lino K, Oliver T, Pietro K, Luu V. 2018. Repeat bleaching of a central Pacific coral reef over the past six decades (1960-2016). Communications Biology 1:177.

Berkelmans R, De'ath G, Kininmonth S, Skirving WJ. 2004. A comparison of the 1998 and 2002 
302

303

304

305

306

307

308

309

310

311

312

313

314

315

316

317

318

319

320

321

322

323

324

coral bleaching events on the Great Barrier Reef: spatial correlation, patterns, and predictions. Coral Reefs 23:74-83. DOI: 10.1007/s00338-003-0353-y.

Beyer HL, Kennedy E V., Beger M, Chen CA, Cinner JE, Darling ES, Eakin CM, Gates RD, Heron SF, Knowlton N, Obura DO, Palumbi SR, Possingham HP, Puotinen M, Runting RK, Skirving WJ, Spalding M, Wilson KA, Wood S, Veron JE, Hoegh-Guldberg O. 2018.

Risk-sensitive planning for conserving coral reefs under rapid climate change. Conservation Letters 6:e12587. DOI: 10.1111/conl.12587.

Bruno J, Siddon C, Witman J, Colin P, Toscano M. 2001. El Nino related coral bleaching in Palau, western Caroline Islands. Coral Reefs 20:127-136.

Center CM. 2012. GHRSST Level 4 CMC0.2deg Global Foundation Sea Surface Temperature Analysis (GDS version 2). DOI: http://dx.doi.org/10.5067/GHCMC-4FM02.

Claar DC, Cobb KM, Baum JK. 2019. In situ and remotely sensed temperature comparisons on a Central Pacific atoll. Coral Reefs 38:1343-1349. DOI: 10.1007/s00338-019-01850-4.

Coffroth MA, Lasker HR, Oliver JK. 1990. Coral Mortality Outside of the Eastern Pacific During 1982-1983: Relationship to El Niño. Elsevier Oceanography Series 52:141-182. DOI: $10.1016 / \mathrm{S} 0422-9894(08) 70035-7$.

Darling ES, McClanahan TR, Maina J, Gurney GG, Graham NAJ, Januchowski-Hartley F, Cinner JE, Mora C, Hicks CC, Maire E, Puotinen M, Skirving WJ, Adjeroud M, Ahmadia G, Arthur R, Bauman AG, Beger M, Berumen ML, Bigot L, Bouwmeester J, Brenier A, Bridge TCL, Brown E, Campbell SJ, Cannon S, Cauvin B, Chen CA, Claudet J, Denis V, Donner S, Estradivari, Fadli N, Feary DA, Fenner D, Fox H, Franklin EC, Friedlander A, Gilmour J, Goiran C, Guest J, Hobbs J-PA, Hoey AS, Houk P, Johnson S, Jupiter SD, Kayal M, Kuo C, Lamb J, Lee MAC, Low J, Muthiga N, Muttaqin E, Nand Y, Nash KL, 
Nedlic O, Pandolfi JM, Pardede S, Patankar V, Penin L, Ribas-Deulofeu L, Richards Z, Roberts TE, Rodgers KS, Safuan CDM, Sala E, Shedrawi G, Sin TM, Smallhorn-West P, Smith JE, Sommer B, Steinberg PD, Sutthacheep M, Tan CHJ, Williams GJ, Wilson S, Yeemin T, Bruno JF, Fortin M-J, Krkosek M, Mouillot D. 2019. Social-environmental

DeCarlo T, Harrison HB. 2019. An enigmatic decoupling between heat stress and coral drivers inform strategic management of coral reefs in the Anthropocene. Nature Ecology \& Evolution 3:1341-1350. DOI: 10.1038/s41559-019-0953-8.

DeCarlo T, Cohen AL, Wong GTF, Davis KA, Lohmann P, Soong K. 2017. Mass coral mortality under local amplification of $2{ }^{\circ} \mathrm{C}$ ocean warming. Scientific Reports 7:44586. DOI:

$$
10.1038 / \text { srep44586. }
$$

DeCarlo TM, Harrison HB, Gajdzik L, Alaguarda D, Rodolfo-Metalpa R, D’Olivo J, Liu G, Patalwala D, McCulloch MT. 2019. Acclimatization of massive reef-building corals to consecutive heatwaves. Proceedings of the Royal Society B: Biological Sciences 286:20190235. DOI: 10.1098/rspb.2019.0235.

Donner SD, Rickbeil GJM, Heron SF, Triebold C, DuBois E, Henss J. 2017. A new, highresolution global mass coral bleaching database. PLOS ONE 12:e0175490. DOI:

10.1371/journal.pone. 0175490 .

ECMWF. 2018.Equitable Threat Score. Available at https://confluence.ecmwf.int/display/FUG/Forecast+User+Guide (accessed September 4, 2019).

Fisk DA, Done TJ. 1985. Taxonomic and bathymetric patterns of bleaching in corals, Myrmidon Reef (Queensland). In: Proceedings of the Fifth International Coral Reef Congress, Tahiti. 
348 Genevier LGC, Jamil T, Raitsos DE, Krokos G, Hoteit I. 2019. Marine heatwaves reveal coral 349 reef zones susceptible to bleaching in the Red Sea. Global Change Biology:gcb.14652. 350 DOI: $10.1111 /$ gcb.14652.

351 Gintert BE, Manzello DP, Enochs IC, Kolodziej G, Carlton R, Gleason ACR, Gracias N. 2018. 352 Marked annual coral bleaching resilience of an inshore patch reef in the Florida Keys: A 353 nugget of hope, aberrance, or last man standing? Coral Reefs 37:533-547. DOI: 10.1007/s00338-018-1678-x.

Glynn PW. 1983. Extensive 'bleaching' and death of reef corals on the Pacific coast of Panama. Environmental Conservation 10:149-154.

Glynn PW. 1993. Coral reef bleaching: ecological perspectives. Coral Reefs 12:1-17. DOI: 10.1007/BF00303779.

Glynn P, Maté J, Baker A, Calderón M. 2001. Coral bleaching and mortality in Panama and Ecuador during the 1997-1998 El Niño-Southern Oscillation event: Spatial/temporal

Glynn PW, Mones AB, Podestá GP, Colbert A, Colgan MW. 2017. El Niño-Southern patterns and comparisons with the 1982-1983 event. BULLETIN OF MARINE SCIENCE Oscillation: Effects on Eastern Pacific Coral Reefs and Associated Biota. In: Glynn P,

Guest JR, Baird AH, Maynard JA, Muttaqin E, Edwards AJ, Campbell SJ, Yewdall K, Affendi Manzello D, Enochs I eds. Coral Reefs of the Eastern Tropical Pacific: Persistence and YA, Chou LM. 2012. Contrasting Patterns of Coral Bleaching Susceptibility in 2010 Suggest an Adaptive Response to Thermal Stress. PLoS ONE 7:e33353. DOI: 10.1371/journal.pone.0033353. 
371 Hamill TM. 1999. Hypothesis Tests for Evaluating Numerical Precipitation Forecasts. Weather

372 and Forecasting 14:155-167. DOI: 10.1175/1520-

373 0434(1999)014<0155:HTFENP>2.0.CO;2.

374 Harriott VJ. 1985. Mortality rates of scleractinian corals before and during a mass bleaching 375 event. Marine Ecology Progress Series 21:81-88. DOI: 10.2307/24816918.

376 Hirahara S, Ishii M, Fukuda Y. 2014. Centennial-Scale Sea Surface Temperature Analysis and 377 Its Uncertainty. Journal of Climate 27:57-75. DOI: 10.1175/JCLI-D-12-00837.1.

378 Hobday A, Oliver E, Sen Gupta A, Benthuysen J, Burrows M, Donat M, Holbrook N, Moore P, 379 Thomsen M, Wernberg T, Smale D. 2018. Categorizing and Naming Marine Heatwaves. $380 \quad$ Oceanography 31. DOI: 10.5670/oceanog.2018.205.

381 van Hooidonk R, Huber M. 2009. Quantifying the quality of coral bleaching predictions. Coral 382 Reefs 28:579-587. DOI: 10.1007/s00338-009-0502-z.

383 Huang B, Angel W, Boyer T, Cheng L, Chepurin G, Freeman E, Liu C, Zhang H-M. 2018.

384 Evaluating SST Analyses with Independent Ocean Profile Observations. Journal of Climate 385 31:5015-5030. DOI: 10.1175/JCLI-D-17-0824.1.

386

387 388 389 390 391 392 393

Huang B, Thorne PW, Banzon VF, Boyer T, Chepurin G, Lawrimore JH, Menne MJ, Smith TM, Vose RS, Zhang H-M. 2017. Extended Reconstructed Sea Surface Temperature, Version 5 (ERSSTv5): Upgrades, Validations, and Intercomparisons. Journal of Climate 30:81798205. DOI: $10.1175 / J C L I-D-16-0836.1$.

Hughes TP, Anderson KD, Connolly SR, Heron SF, Kerry JT, Lough JM, Baird AH, Baum JK, Berumen ML, Bridge TC, Claar DC, Eakin CM, Gilmour JP, Graham NAJ, Harrison H, Hobbs J-PA, Hoey AS, Hoogenboom M, Lowe RJ, McCulloch MT, Pandolfi JM, Pratchett M, Schoepf V, Torda G, Wilson SK. 2018. Spatial and temporal patterns of mass bleaching 
of corals in the Anthropocene. Science 359:80-83. DOI: 10.1126/science.aan8048.

395 Hughes TP, Kerry JT, Álvarez-Noriega M, Álvarez-Romero JG, Anderson KD, Baird AH,

396 Babcock RC, Beger M, Bellwood DR, Berkelmans R, Bridge TC, Butler IR, Byrne M,

397 Cantin NE, Comeau S, Connolly SR, Cumming GS, Dalton SJ, Diaz-Pulido G, Eakin CM,

398 Figueira WF, Gilmour JP, Harrison HB, Heron SF, Hoey AS, Hobbs J-PA, Hoogenboom

399 MO, Kennedy E V., Kuo C, Lough JM, Lowe RJ, Liu G, McCulloch MT, Malcolm HA,

400 McWilliam MJ, Pandolfi JM, Pears RJ, Pratchett MS, Schoepf V, Simpson T, Skirving WJ,

401 Sommer B, Torda G, Wachenfeld DR, Willis BL, Wilson SK. 2017. Global warming and

402 recurrent mass bleaching of corals. Nature 543:373-377. DOI: 10.1038/nature21707.

403 Hughes TP, Kerry JT, Connolly SR, Baird AH, Eakin CM, Heron SF, Hoey AS, Hoogenboom

404 MO, Jacobson M, Liu G, Pratchett MS, Skirving W, Torda G. 2019. Ecological memory

405 modifies the cumulative impact of recurrent climate extremes. Nature Climate Change

406 9:40-43. DOI: 10.1038/s41558-018-0351-2.

407 Kennedy JJ, Rayner NA, Atkinson CP, Killick RE. 2019. An Ensemble Data Set of Sea Surface

408 Temperature Change From 1850: The Met Office Hadley Centre HadSST.4.0.0.0 Data Set.

409 Journal of Geophysical Research: Atmospheres 124:7719-7763. DOI:

410 10.1029/2018JD029867.

411 Lapointe BE, Brewton RA, Herren LW, Porter JW, Hu C. 2019. Nitrogen enrichment, altered 412 stoichiometry, and coral reef decline at Looe Key, Florida Keys, USA: a 3-decade study. 413 Marine Biology 166:108. DOI: 10.1007/s00227-019-3538-9.

414 Liu G, Heron S, Eakin C, Muller-Karger F, Vega-Rodriguez M, Guild L, De La Cour J, Geiger

415 E, Skirving W, Burgess T, Strong A, Harris A, Maturi E, Ignatov A, Sapper J, Li J, Lynds

416 S. 2014. Reef-scale thermal stress monitoring of coral ecosystems: new 5-km global 
products from NOAA Coral Reef Watch. Remote Sensing 6:11579-11606. DOI: 10.3390/rs61111579.

419

420

421

422

423

424

425

426

427

428

429

430

431

432

433

434

435

436

437

438

439

Liu G, Strong AE, Skirving W. 2003. Remote sensing of sea surface temperatures during 2002 Barrier Reef coral bleaching. Eos, Transactions American Geophysical Union 84:137-141. DOI: $10.1029 / 2003 E O 150001$.

Liu G, Strong A, Skirving W, Arzayus L. 2006. Overview of NOAA coral reef watch program's near-real time satellite global coral bleaching monitoring activities. In: Proceedings of the 10th International Coral Reef Symposium: Okinawa.

Logan C, Dunne J, Eakin C, Donner S. 2012. A framework for comparing coral bleaching thresholds. In: Proceedings of the 12th International Coral Reef Symposium, Cairns, Australia.

Logan CA, Dunne JP, Eakin CM, Donner SD. 2014. Incorporating adaptive responses into future projections of coral bleaching. Global Change Biology 20:125-139. DOI: $10.1111 /$ gcb.12390.

McClanahan TR, Darling ES, Maina JM, Muthiga NA, 'agata SD, Jupiter SD, Arthur R, Wilson SK, Mangubhai S, Nand Y, Ussi AM, Humphries AT, Patankar VJ, Guillaume MMM, Keith SA, Shedrawi G, Julius P, Grimsditch G, Ndagala J, Leblond J. 2019. Temperature patterns and mechanisms influencing coral bleaching during the 2016 El Niño. Nature Climate Change 9:845-851. DOI: 10.1038/s41558-019-0576-8.

Mollica NR, Cohen AL, Alpert AE, Barkley HC, Brainard RE, Carilli JE, DeCarlo TM, Drenkard EJ, Lohmann P, Mangubhai S, Pietro KR, Rivera HE, Rotjan RD, Scott-Buechler C, Solow AR, Young CW. 2019. Skeletal records of bleaching reveal different thermal thresholds of Pacific coral reef assemblages. Coral Reefs 38:743-757. DOI: 
441 Oliver J. 1985. Recurrent seasonal bleaching and mortality of corals on the Great Barrier Reef.

442

443

444

445

446

447

448

449

450

451

452

453

454

455

456

457

458

459

460

461

462

In: Proceedings of the Fifth International Coral Reef Congress, Tahiti.

Podestá GP, Glynn PW. 1997. Sea surface temperature variability in Panamá and Galápagos: Extreme temperatures causing coral bleaching. Journal of Geophysical Research: Oceans 102:15749-15759. DOI: 10.1029/96JC03557.

Pratchett MS, McCowan D, Maynard JA, Heron SF. 2013. Changes in Bleaching Susceptibility among Corals Subject to Ocean Warming and Recurrent Bleaching in Moorea, French Polynesia. PLoS ONE 8:e70443. DOI: 10.1371/journal.pone.0070443.

Rayner NA, Parker DE, Horton EB, Folland CK, Alexander L V., Rowell DP, Kent EC, Kaplan A. 2003. Global analyses of sea surface temperature, sea ice, and night marine air temperature since the late nineteenth century. Journal of Geophysical Research 108:4407. DOI: $10.1029 / 2002 J D 002670$.

Reynolds RW, Smith TM, Liu C, Chelton DB, Casey KS, Schlax MG. 2007. Daily highresolution-blended analyses for sea surface temperature. Journal of Climate 20:5473-5496. DOI: $10.1175 / 2007 J C L I 1824.1$.

Safaie A, Silbiger NJ, McClanahan TR, Pawlak G, Barshis DJ, Hench JL, Rogers JS, Williams GJ, Davis KA. 2018. High frequency temperature variability reduces the risk of coral bleaching. Nature Communications 9:1671. DOI: 10.1038/s41467-018-04074-2.

Skirving W, Enríquez S, Hedley J, Dove S, Eakin C, Mason R, De La Cour J, Liu G, HoeghGuldberg O, Strong A, Mumby P, Iglesias-Prieto R, Skirving W, Enríquez S, Hedley JD, Dove S, Eakin CM, Mason RAB, De La Cour JL, Liu G, Hoegh-Guldberg O, Strong AE, Mumby PJ, Iglesias-Prieto R. 2017. Remote Sensing of Coral Bleaching Using Temperature 
463 and Light: Progress towards an Operational Algorithm. Remote Sensing 10:18. DOI:

$464 \quad 10.3390 /$ rs 10010018.

465 Smith NP. 2001. Weather and hydrographic conditions associated with coral bleaching: Lee

466 Stocking Island, Bahamas. Coral Reefs 20:415-422. DOI: 10.1007/s00338-001-0189-2.

467 Sully S, Burkepile DE, Donovan MK, Hodgson G, van Woesik R. 2019. A global analysis of 468 coral bleaching over the past two decades. Nature Communications 10:1264. DOI:

$469 \quad 10.1038 / \mathrm{s} 41467-019-09238-2$.

470 Thompson DM, van Woesik R. 2009. Corals escape bleaching in regions that recently and 471 historically experienced frequent thermal stress. Proceedings of the Royal Society B:

472 Biological Sciences 276:2893-2901. DOI: 10.1098/rspb.2009.0591.

473 


\section{$474 \quad$ Figure captions}

475

476 Figure 1. Comparison of global-mean annual sea surface temperature (SST) anomalies among

477 various SST products. (A) Global-mean SST anomalies from 1982-2016, (B) the same data but 478 detrended, and (C) Principal component analysis (PCA) of the detrended annual SST anomalies.

479 (D-H) Pairwise differences of the global-mean anomalies between Coral Reef Watch (CRW) and 480 the other SST products (black) plotted alongside PC2 (light blue). Note that although PC has 481 arbitrary units, it mainly tracks the mismatches between Coral Reef Watch and other products.

482

483

484 485 486 487 488

489

490 491 492 493 494 495

Figure 2. Reconstructing coral bleaching events with degree heating weeks (DHW). The four panels show the numbers of (A) hits, (B) false alarms, (C) misses, and (D) correct negatives when bleaching events are predicted for 100 globally-distributed reef systems using various DHW thresholds (colors). The black line indicates the optimal DHW threshold $\left(6.3^{\circ} \mathrm{C}\right.$-weeks $)$ determined by the Equitable Threat Score (ETS; see below).

Figure 3. ETS for the globally-distributed bleaching events using various predictors and responses. (A) The analysis was performed with various time windows used to define DHW (yellow to purple colors), DHW including the $1{ }^{\circ} \mathrm{C}$ above the MMM cutoff (green; using a 12week window), maximum Hotspots (light blue), maximum Marine Heatwave (MHW) index (black), or only for severe bleaching events (magenta; using DHW with a 9-week window). Comparison of the green line with the darkest purple line shows the change in absolute value of DHW when including or excluding, respectively, the $1{ }^{\circ} \mathrm{C}$ above the MMM cutoff in the DHW 
496 definition. (B) Maximum ETS achieved with each of the temperature predictors that were

497 evaluated here.

498

499 Figure 4. Forecasting metrics for the skill of reconstructing coral bleaching events from DHW.

500 The analysis was performed regionally (colored lines) and globally (black line). The definitions

501 of the various metrics (A-I) are listed in Table 2. The dark gray circles indicate the metric values

502 corresponding to the optimal DHW threshold, as determined by the maximum ETS.

503

504 Figure 5. Evaluation of multivariate predictions of coral bleaching events. Colors indicate the 505 ETS score for various combinations of the predictors, and black contours show the top $2 \%$ of 506 ETS scores. The main analysis was repeated using DHW (with a 9-week window) as a predictor 507 and including a DHW-threshold trend (A), or an El Niño threshold (B). In the trend analysis, the 508 DHW threshold on the y-axis shows the threshold during 1999. The El Niño index is defined as 509 the mean SST anomaly (relative to the 1900-2018 monthly climatology in HadISST; Rayner et 510 al., 2003) in the Nino3.4 region, and the threshold is taken as the maximum El Niño index per 511 year. 
Figure 1

Comparison of global-mean annual sea surface temperature (SST) anomalies among various SST products.

(A) Global-mean SST anomalies from 1982-2016, (B) the same data but detrended, and (C) Principal component analysis (PCA) of the detrended annual SST anomalies. (D-H) Pairwise differences of the global-mean anomalies between Coral Reef Watch (CRW) and the other SST products (black) plotted alongside PC2 (light blue). Note that although PC has arbitrary units, it mainly tracks the mismatches between Coral Reef Watch and other products.
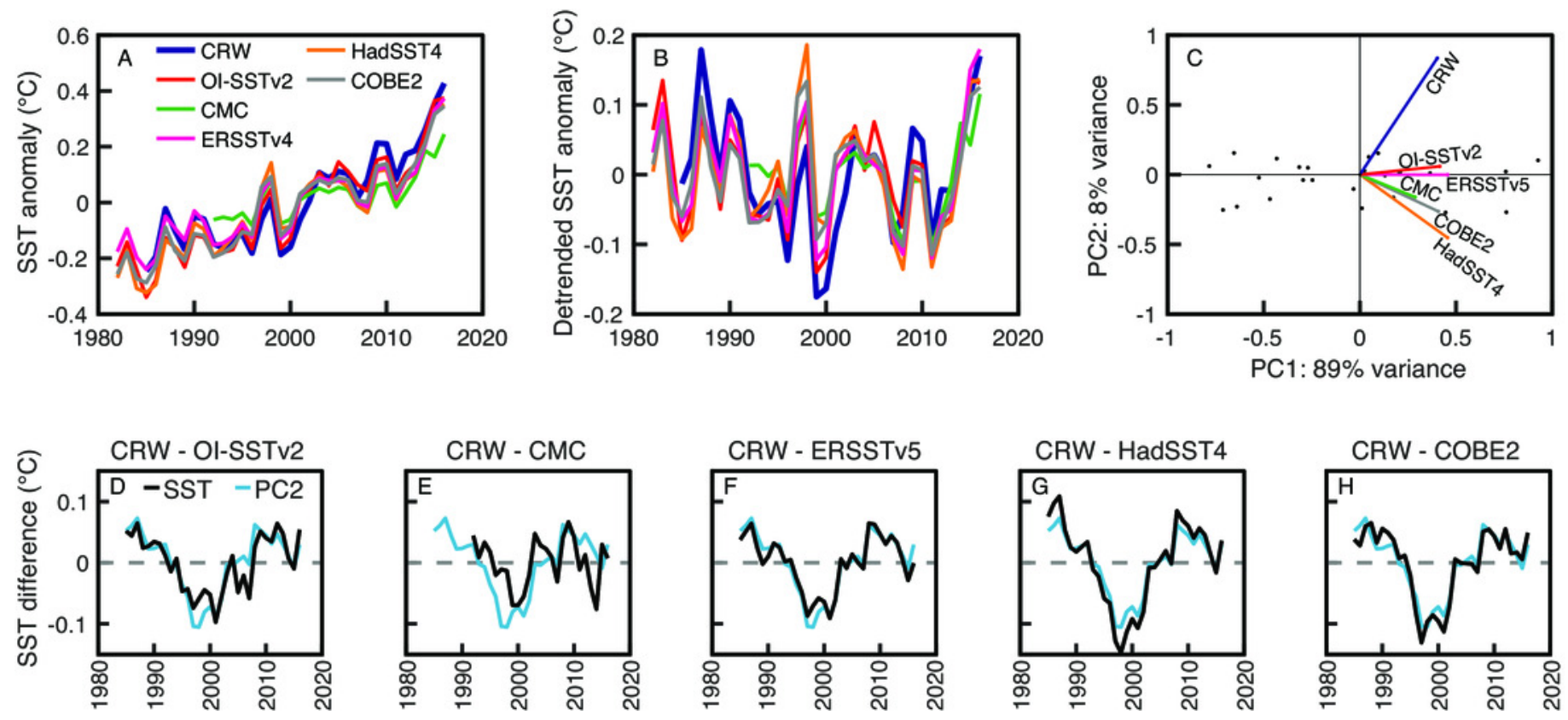
Figure 2

Reconstructing coral bleaching events with degree heating weeks (DHW).

The four panels show the numbers of $(A)$ hits, $(B)$ false alarms, (C) misses, and (D) correct negatives when bleaching events are predicted for 100 globally-distributed reef systems using various DHW thresholds (colors). The black line indicates the optimal DHW threshold (6.3 ${ }^{\circ} \mathrm{C}$-weeks) determined by the Equitable Threat Score (ETS; see below).

\section{Hits}

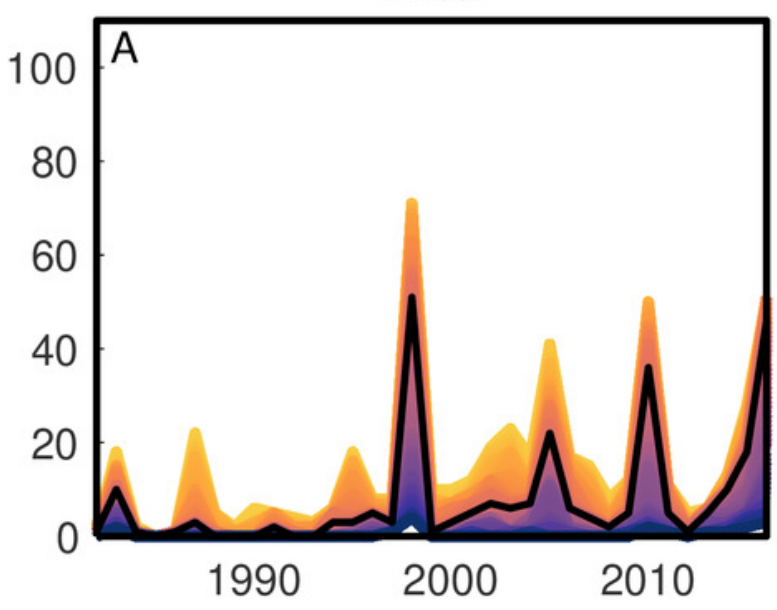

Misses

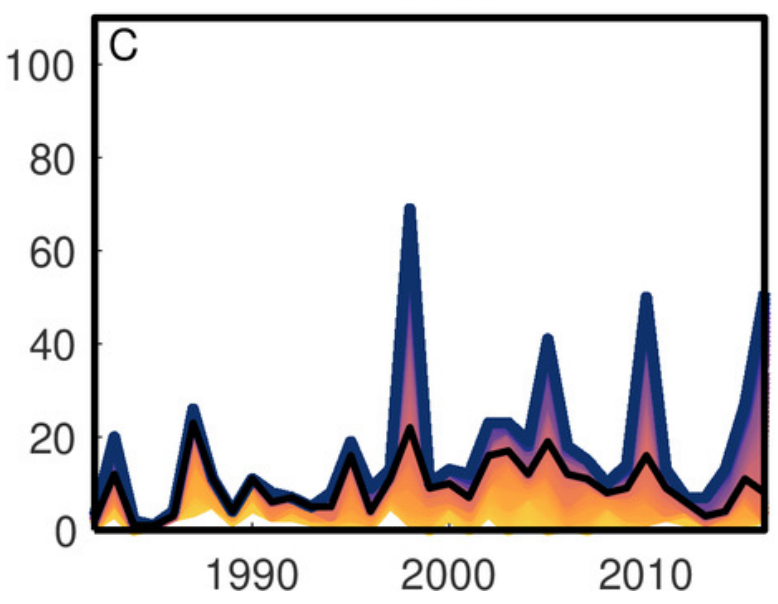

False Alarms

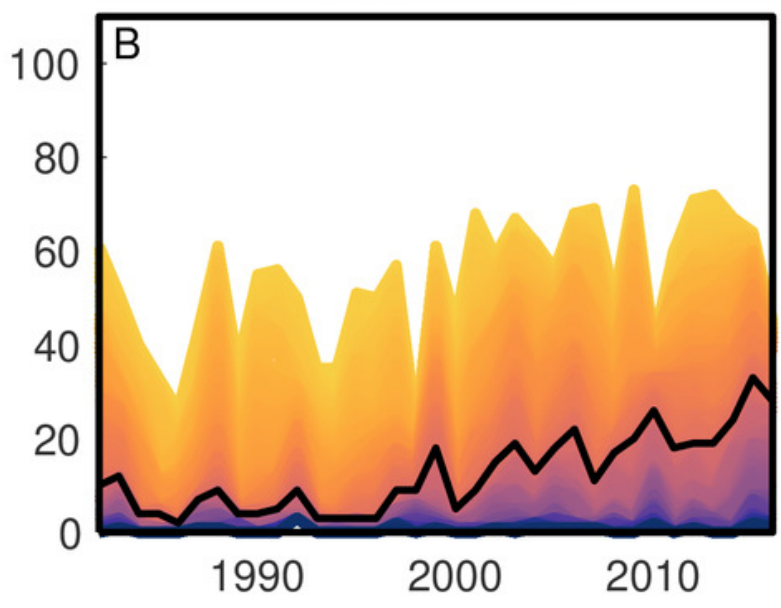

Correct Negatives

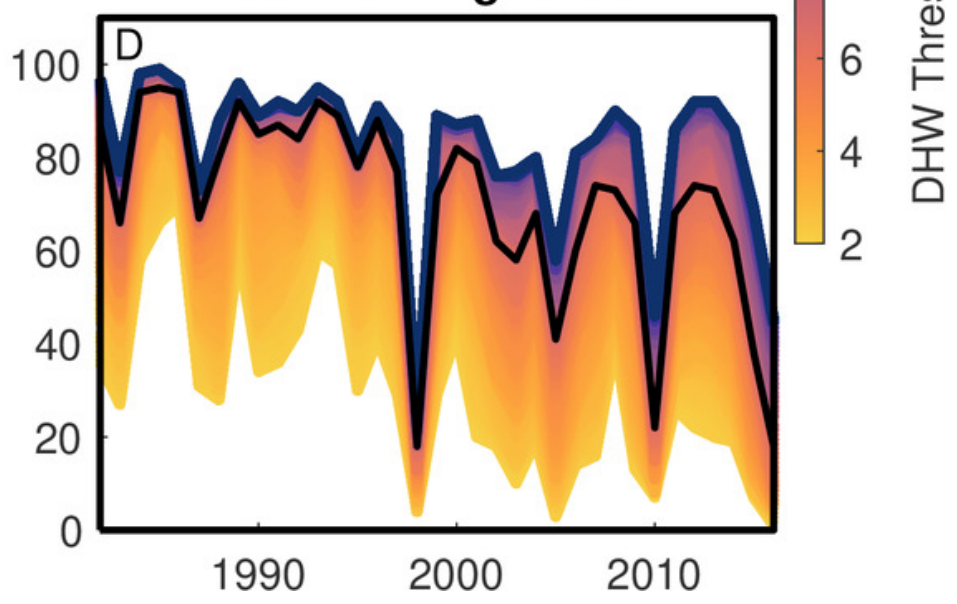




\section{Figure 3}

ETS for the globally-distributed bleaching events using various predictors and responses.

(A) The analysis was performed with various time windows used to define DHW (yellow to purple colors), DHW including the $1^{\circ} \mathrm{C}$ above the MMM cutoff (green; using a 12-week window), maximum Hotspots (light blue), maximum Marine Heatwave (MHW) index (black), or only for severe bleaching events (magenta; using DHW with a 9-week window).

Comparison of the green line with the darkest purple line shows the change in absolute value of DHW when including or excluding, respectively, the $1{ }^{\circ} \mathrm{C}$ above the MMM cutoff in the DHW definition. (B) Maximum ETS achieved with each of the temperature predictors that were evaluated here.
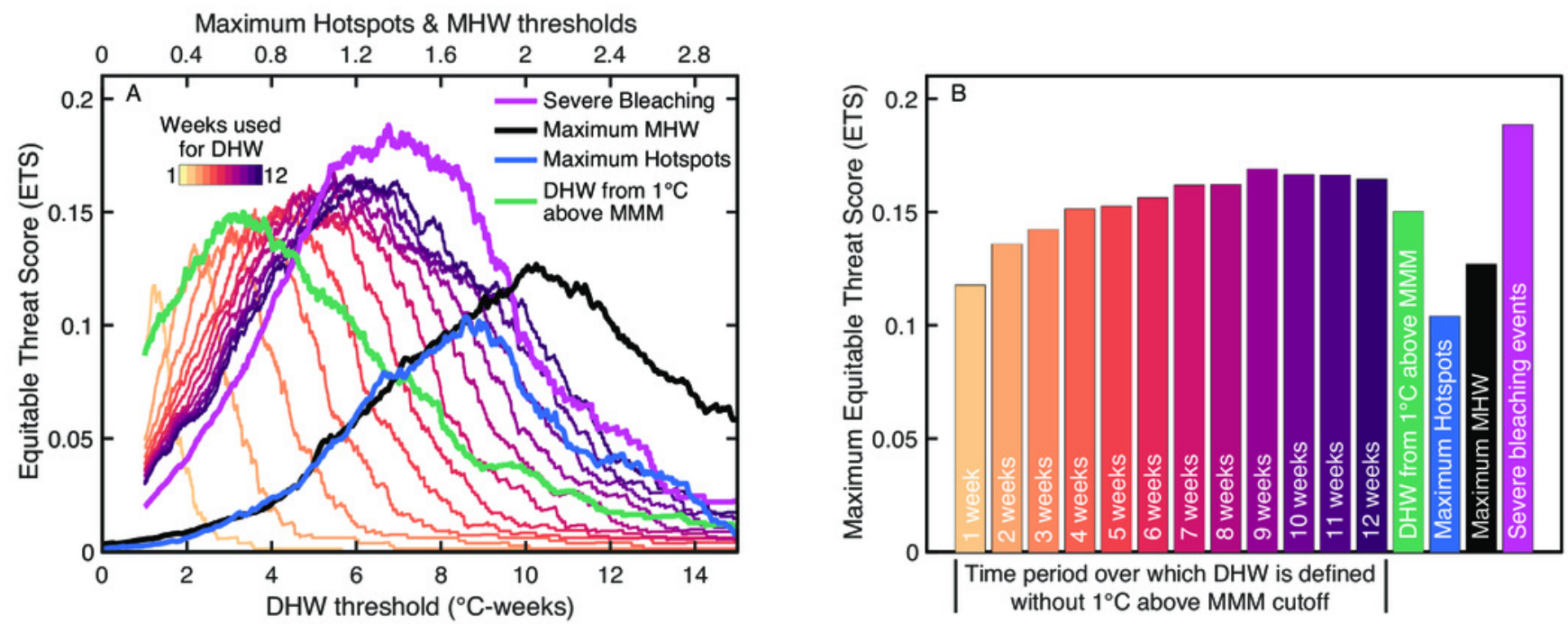
Figure 4

Forecasting metrics for the skill of reconstructing coral bleaching events from DHW.

The analysis was performed regionally (colored lines) and globally (black line). The definitions of the various metrics (A-I) are listed in Table 2. The dark gray circles indicate the metric values corresponding to the optimal DHW threshold, as determined by the maximum ETS.
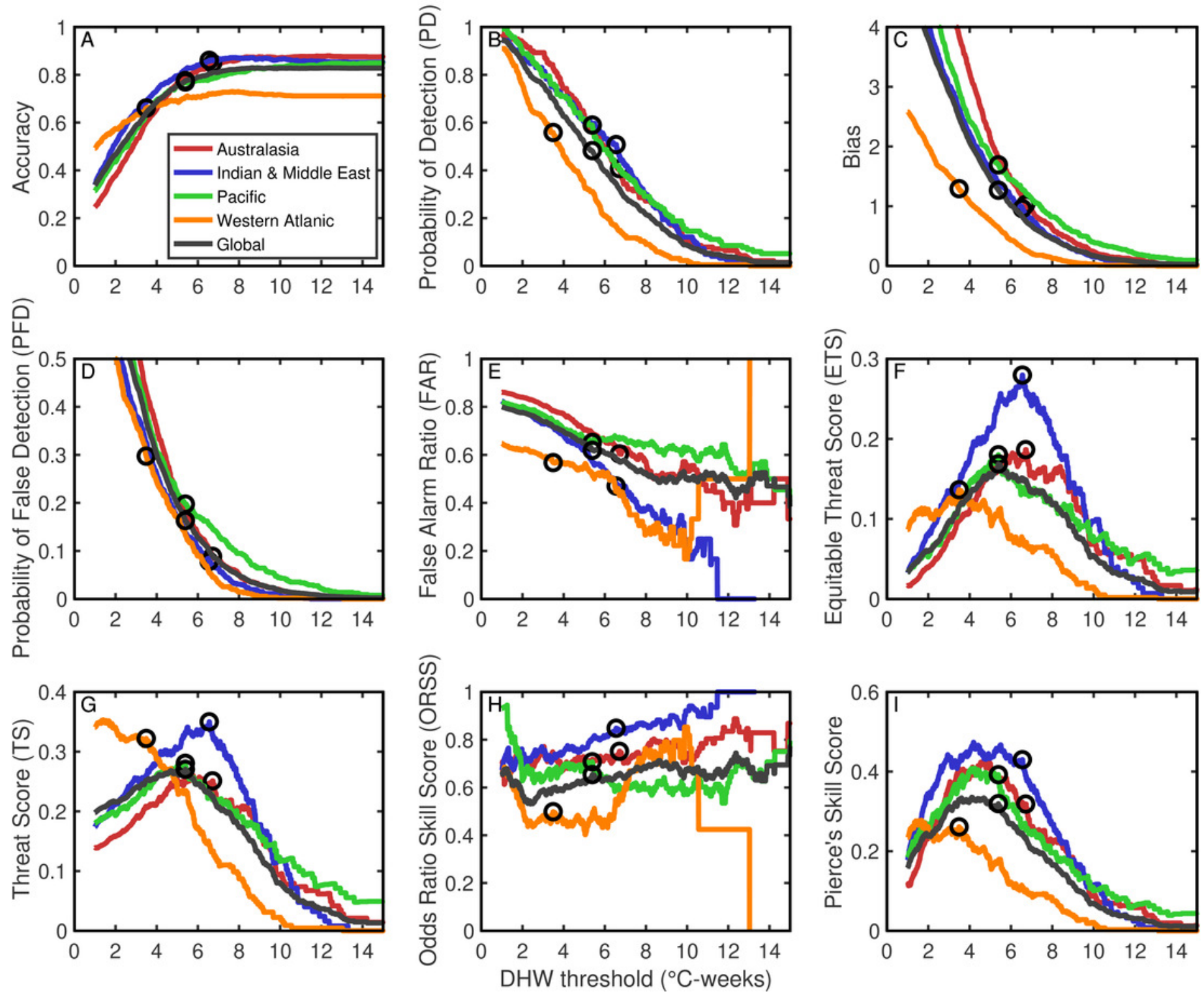


\section{Figure 5}

Evaluation of multivariate predictions of coral bleaching events.

Colors indicate the ETS score for various combinations of the predictors, and black contours show the top $2 \%$ of ETS scores. The main analysis was repeated using DHW (with a 9-week window) as a predictor and including a DHW-threshold trend (A), or an El Niño threshold (B). In the trend analysis, the DHW threshold on the y-axis shows the threshold during 1999. The El Niño index is defined as the mean SST anomaly (relative to the 1900-2018 monthly climatology in HadISST; Rayner et al., 2003) in the Nino3.4 region, and the threshold is taken as the maximum El Niño index per year.

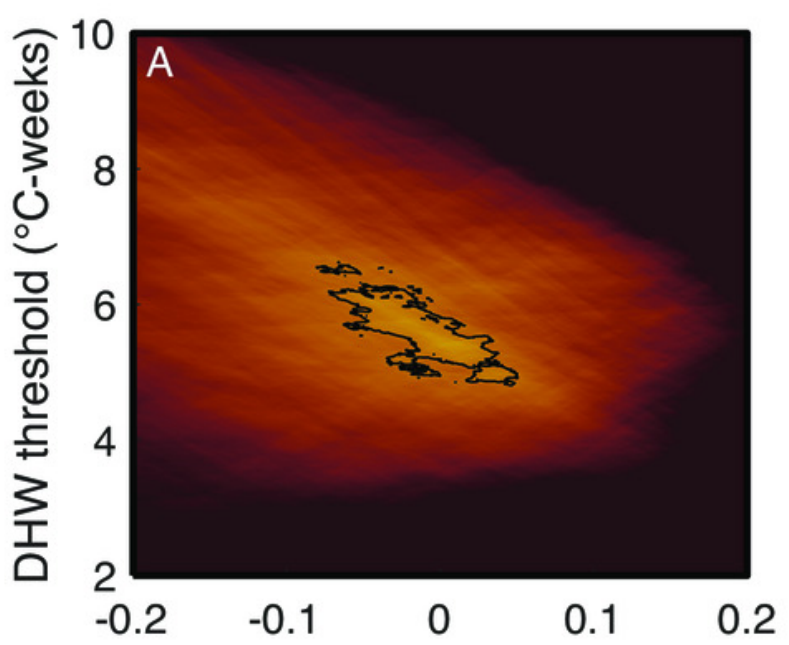

DHW trend $\left({ }^{\circ} \mathrm{C}\right.$-week $\left.\mathrm{yr}^{-1}\right)$

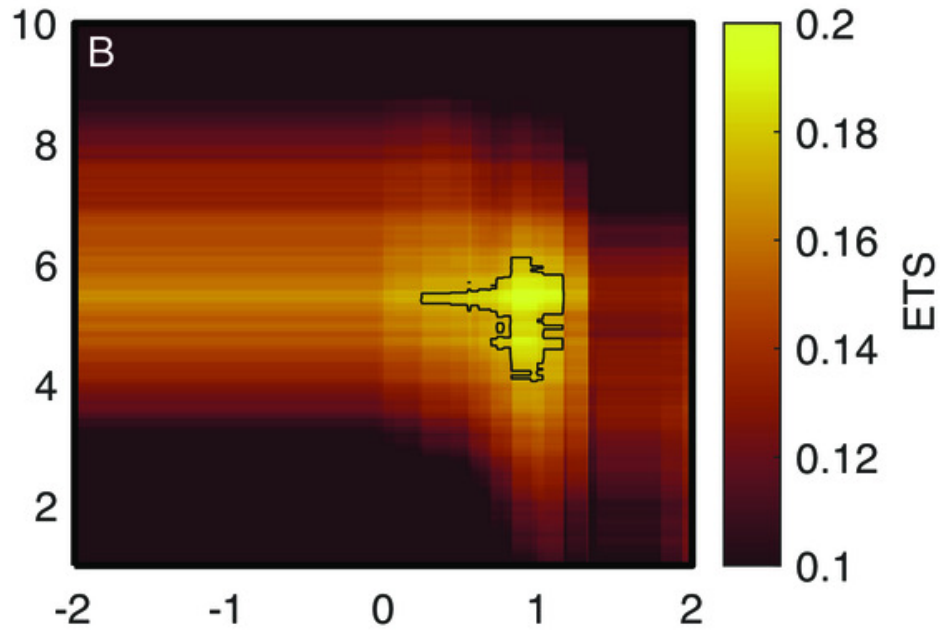

El Niño threshold 


\section{Table 1 (on next page)}

Table 1. Schematic contingency table of observed and predicted events. 
1 Table 1. Schematic contingency table of observed and predicted events.

2

Observed

\begin{tabular}{|c|c|c|c|}
\hline \multirow{3}{*}{ Predicted } & & yes & no \\
\hline & yes & Hits (“' $H$ ”) & False Alarms (" $F A$ ") \\
\hline & & Misses (" $M$ ') & Correct Negatives (“ $C N$ ') \\
\hline
\end{tabular}




\section{Table 2 (on next page)}

Metrics to assess the binary (presence/absence) detection of events. 
1 Table 2. Metrics to assess the binary (presence/absence) detection of events. The various metrics,

2 formulas, meanings, and ranges are displayed.

\begin{tabular}{|c|c|c|c|}
\hline Test & Formula & Meaning & Range \\
\hline Accuracy & $(H+C N) / \mathrm{n}$ & Fraction of predictions correct & $\begin{array}{l}0 \text { to } 1 \\
1=\text { perfect } \\
0.5=\text { no skill }\end{array}$ \\
\hline Bias & $(H+F A) /(H+M)$ & $\begin{array}{l}\text { Predicted "yes" relative to observed } \\
\text { "yes" }\end{array}$ & $\begin{array}{l}0 \text { to infinity } \\
1=\text { perfect }\end{array}$ \\
\hline $\begin{array}{l}\text { Probability of } \\
\text { Detection (PD) }\end{array}$ & $H /(H+M)$ & $\begin{array}{l}\text { Fraction observed "yes" were } \\
\text { Predicted }\end{array}$ & $\begin{array}{l}0 \text { to } 1 \\
1=\text { perfect } \\
0.5=\text { no skill }\end{array}$ \\
\hline $\begin{array}{l}\text { Probability of False } \\
\text { Detection (PFD) }\end{array}$ & $F A /(C N+F A)$ & $\begin{array}{l}\text { Fraction of observed "no" were } \\
\text { predicted "yes" }\end{array}$ & $\begin{array}{l}0 \text { to } 1 \\
0=\text { perfect }\end{array}$ \\
\hline False Alarm Ratio & $F A /(H+F A)$ & $\begin{array}{l}\text { Fraction of predicted "yes" were not } \\
\text { observed }\end{array}$ & $\begin{array}{l}0 \text { to } 1 \\
0=\text { perfect }\end{array}$ \\
\hline $\begin{array}{l}\text { Equitable Threat } \\
\text { Score (ETS) }\end{array}$ & $\begin{array}{l}H /(H+F A+M- \\
\left.H_{\text {random }}\right)\end{array}$ & $\begin{array}{l}\text { Correspondence of predicted events } \\
\text { to observed events, but accounting } \\
\text { for hits due to random chance }\end{array}$ & $\begin{array}{l}-1 / 3 \text { to } 1 \\
1=\text { perfect } \\
0=\text { no skill }\end{array}$ \\
\hline Threat Score (TS) & $H /(H+F A+M)$ & $\begin{array}{l}\text { Correspondence of predicted events } \\
\text { to observed events }\end{array}$ & $\begin{array}{l}0 \text { to } 1 \\
1=\text { perfect } \\
0=\text { no skill }\end{array}$ \\
\hline $\begin{array}{l}\text { Odds Ratio Skill } \\
\text { Score (ORSS) }\end{array}$ & $\frac{\left(H^{*} C N-M^{*} F A\right)}{\left(H^{*} C N+M^{*} F A\right)}$ & $\begin{array}{l}\text { The improvement of predictions } \\
\text { above random chance }\end{array}$ & $\begin{array}{l}-1 \text { to } 1 \\
1=\text { perfect } \\
0=\text { no skill }\end{array}$ \\
\hline Pierce's Skill Score & $\begin{array}{l}H /(H+M)- \\
F A /(F A+C N)\end{array}$ & $\begin{array}{l}\text { Separation of events from non- } \\
\text { events }\end{array}$ & $\begin{array}{l}-1 \text { to } 1 \\
1=\text { perfect } \\
0=\text { no skill }\end{array}$ \\
\hline
\end{tabular}

3 Note: $H_{\text {random }}=(H+F A) *(H+M) / n$, where $n$ is the total number of observations $(3,500$ in this case $)$ 
Table 3 (on next page)

Changes in ETS and Bias associated with different bleaching predictors and responses. 
1 Table 3. Changes in ETS and Bias associated with different bleaching predictors and responses.

\begin{tabular}{|c|c|c|c|}
\hline Conditions evaluated & Max ETS & $\Delta$ ETS & Bias at max ETS \\
\hline Including $1{ }^{\circ} \mathrm{C}$ cutoff for $\mathrm{DHW}$ & 0.1500 & - & 0.9867 \\
\hline Excluding $1{ }^{\circ} \mathrm{C}$ cutoff for $\mathrm{DHW} \mathrm{W}^{\mathrm{a}, \mathrm{b}, \mathrm{d}}$ & 0.1643 & +0.0143 & 1.1708 \\
\hline DHW defined with 9-week window ${ }^{\mathrm{a}, \mathrm{c}, \mathrm{d}}$ & 0.1688 & $+0.0045^{*}$ & 1.2670 \\
\hline Including El Niño threshold ${ }^{\mathrm{a}, \mathrm{c}, \mathrm{d}}$ & 0.1983 & +0.0295 & 0.8342 \\
\hline Including regional DHW thresholds ${ }^{\mathrm{a}, \mathrm{c}, \mathrm{d}}$ & 0.2035 & +0.0338 & 1.2405 \\
\hline Including El Niño and regional DHW thresholds ${ }^{\mathrm{a}, \mathrm{c}, \mathrm{d}}$ & 0.2182 & +0.0495 & 0.8242 \\
\hline Only "severe" bleaching events c,d & 0.1883 & +0.0195 & 1.4749 \\
\hline Maximum Hotspots ${ }^{\mathrm{a}}$ & 0.1038 & -0.0650 & 1.4245 \\
\hline Maximum Marine Heatwave index ${ }^{\mathrm{a}}$ & 0.1268 & -0.0420 & 0.9784 \\
\hline
\end{tabular}

2 analysis of bleaching presence (including "moderate" and "severe") versus absence

$3{ }^{b} \mathrm{DHW}$ defined with 12-week window

$4{ }^{c} \mathrm{DHW}$ defined with 9-week window

$5{ }^{d} \mathrm{DHW}$ defined without the $1^{\circ} \mathrm{C}$ cutoff

6 *all subsequent $\triangle E T S$ are relative to this value

7 